\title{
Implementing learning analytics: The journey to improve teaching and learning at five Australian universities
}

\author{
Jo-Anne Clark, David Tuffley \\ Griffith University
}

\begin{abstract}
Universities are under heightened pressure to become more efficient using less resources., the quality of teaching and the student experience must not be sacrificed in pursuit of efficiency. One strategy is to use automation, smart technology to augment the work of human teachers. Not to replace the teacher but to make them better at what they do. Give them smart tools to do their jobs more effectively. Learning Analytics is one such tool that has the potential to leverage teaching capability. This paper examines the learning analytics implementations at five diverse Australian universities (regional and metropolitan) with varying degrees of success reported. These implementations are evaluated using of DeLone and McLean's (2003) information system success model. It will be seen that participants in this interpretivist case study regard learning analytics as having potential benefits but are not sure about how best to realise analytics systems with extensive usability research built-in and offering sophisticated functionality seem likely to emerge and take precedence over the trial and error approach. This study addresses an apparent gap in the research as limited studies exist targeting both learning analytics and information system success.
\end{abstract}

Keywords: Learning Analytics, Information System Success, Teaching and Learning, Information System Success Model

\section{Introduction}

To provide historical context, learning analytics is a relative newcomer to higher education, having developed quite rapidly over the past decade. Proactive teachers are increasingly using learning analytics in their teaching and learning practice to optimise learning outcomes (Mangaroska \& Giannakos, 2019). These developments include improved capabilities to capture, curate, manage and analyse data into actionable information about learners, their activities, and outcomes. Said data is accumulating in ever-greater quantities and has called for the development of advanced analytics with which to derive actionable insights (Greller \& Draschler, 2012). Meanwhile, COVID-19 has placed enormous strain upon the University sector from several directions; reduced international student income, subsequent loss of teaching staff, as well as the difficulties of running on-line courses by staff more accustomed to face-to-face delivery. Even before these challenges, it was clearly evident that attracting and retaining students is vitally important (Universities Australia, 2020; West, et, al., 2015). In response, learning analytics has emerged as a potentially powerful technology to allow teaching staff to enhance their effectiveness in the face of staff reductions to create a high-quality student experience (Colvin et al., 2016).

Though a relatively young field of study, learning analytics has the potential to improve the quality of teaching and learning through giving quantitative insights into what works and what does not, enabling the student experience to be optimised (Dawson, et al., 2019). Learning analytics allows the measurement of teaching. The importance of measurement has been noted by leading educator Peter Drucker who observed that one cannot improve a process without first measuring it (Drucker, 1995).

Research supports the common-sense view that students perform better when given adequate support from their university (James, Krause \& Jennings 2010). Learning analytics provides an additional layer of support to students in terms of pastoral care and/or checking which type of resources have the best effect in a course. Krause \& Coates (2008) make a strong case for the utilization of teaching and learning technologies, such as learning analytics systems, to play an important role in students' early engagement with the university. 


\section{Defining Learning Analytics?}

There are many definitions of LA within the academic literature. LA can be defined as the use of studentgenerated data for the prediction of educational outcomes or for the purpose of tailoring education (Junco \& Clem, 2015; Xing, Guo, Petakovic, \& Goggins, 2015). Others define learning analytics as a tool to help educators examine, understand, and support students' study behaviours and change their learning environments (Drachsler \& Kalz, 2012; Rubel \& Jones, 2016; Alhadad, 2018; Siemens, Dawson \& Lynch, 2014; Dawson et al., 2019). Donoghue, Horvath \& Lodge (2019) describe LA as an emerging field for the purpose of supporting, enhancing, facilitating, predicting, and measuring human learning in an educational setting. This research will use the definition from the First International Conference on Learning Analytics and Knowledge (LAK2011).

"Learning analytics is the measurement, collection, analysis and reporting of data about learners and their contexts, for purposes of understanding and optimising learning and the environments in which it occurs. " This definition was chosen as it is widely accepted in the field of LA research.

We examine the application of the DeLone and McLean (2003) model of Information Systems Success to five large Australian universities focusing on their LA systems. These examples of digital intervention are helpful to illuminate issues associated with learning and teaching supported by learning analytics. The learning analytics systems are dissected by the researcher and interviewees to explore whether the system has in fact been a successful implementation. The learning analytics system is categorised by definition as an information system. DeLone and McLean's (2003) model details a comprehensive framework for assessing the performance of information systems in organizations. This model has been tried and tested over many years and in many examples, but these studies have had a quantitative focus. Currently no studies exist examining learning analytics systems success using a qualitative lens. So much of the research on LA focuses on educational examples including learning design, student engagement and student performance, but studies are yet to look at the perceptions of users, on whether the implementation of the LA system actually works. This study addresses this point.

\section{Information Systems Success}

Learning Analytics systems have been classified as belonging to the broad category of information systems. An information system involves gathering, processing, distributing and using information by input, processing and output, with a storage and feedback component (Beynon-Davies, 2013). We argue that learning analytics can be classified as an information system by virtue of the systems under investigation being categorised as systems which process, collect, evaluate, analyse, and report organizational data for the purpose of decision making (Campbell \& Oblinger, 2007). The track record for successful information systems implementations is not particularly good (Nguyen, Nguyen \& Cao, 2015). In fact, seventy-five percent of information systems/software implementations are a deemed a failure wherein the software is never completed, or systems are not utilised (Beynon-Davies, 2013). In this paper, the authors apply the information systems success literature to the implementation of Learning Analytics systems.

The literature on information systems success is extensive, having accumulated over decades. The authors have updated the original model from 1992 after contributions from many IS scholars to improve the model (DeLone $\&$ McLean, 1992). The information systems success model has been cited in literally thousands of papers and has been one of the most influential theories in contemporary information systems research (Nguyen, Nguyen \& Cao, 2015). It provides a solid foundation for examining the success or otherwise of Learning Analytics implementation, particularly in relation to the strategic improvement of learning and teaching outcomes. This research uses the latest version of the model.

The DeLone \& McLean model uses three classifications to categorise information systems success (Figure 1). The first area examines the Information Communication Technology (ICT) system or functionality of the system. The second focuses on the usability of the system, particularly how users interact with the system and whether the system interface is user friendly. Also, does the system achieve its intended goal. The third element examines the overall net benefits of the system, including how the information system's overall impact is felt as both an individual and an organization (Nguyen, Nguyen \& Cao, 2015; Beynon-Davies, 2013). 
Figure 1: The updated DeLone-McLean information system success model (DeLone and McLean, 2003).

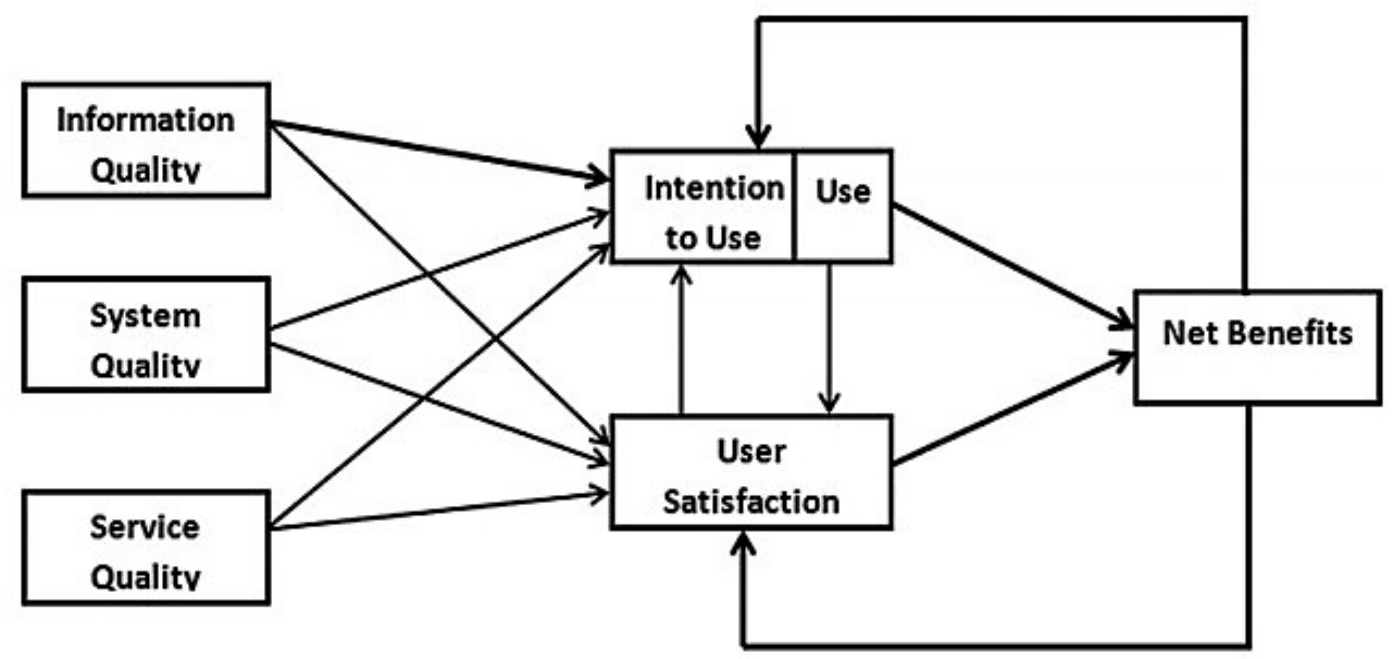

Studies using the DeLone \& McLean (2003) model are usually quantitative studies, but some qualitative studies do exist, and they are increasing. Petter, DeLone \& McLean (2008) did an extensive review of the use of the model and out of the 180 studies examined, only the following qualitative studies were mentioned: Coombs et al., 2001, Scheepers et al., 2006 and Leclercq, 2007. In an interesting adaptation, Hosapple \& Lee-Post (2006) apply the DeLone \& McLean (2003) using an e-learning perspective. The authors posit that the overall success of an e-learning application depends on achieving success at all of the three stages of the development of an elearning system, namely system design, system delivery and the system outcome. In Figure 2, the authors have shown the adaption of the original model as applied to e-learning systems implementation.

Figure 2: The E-Learning Success Model and sample metrics (Holsapple \& Lee-Post, 2006).

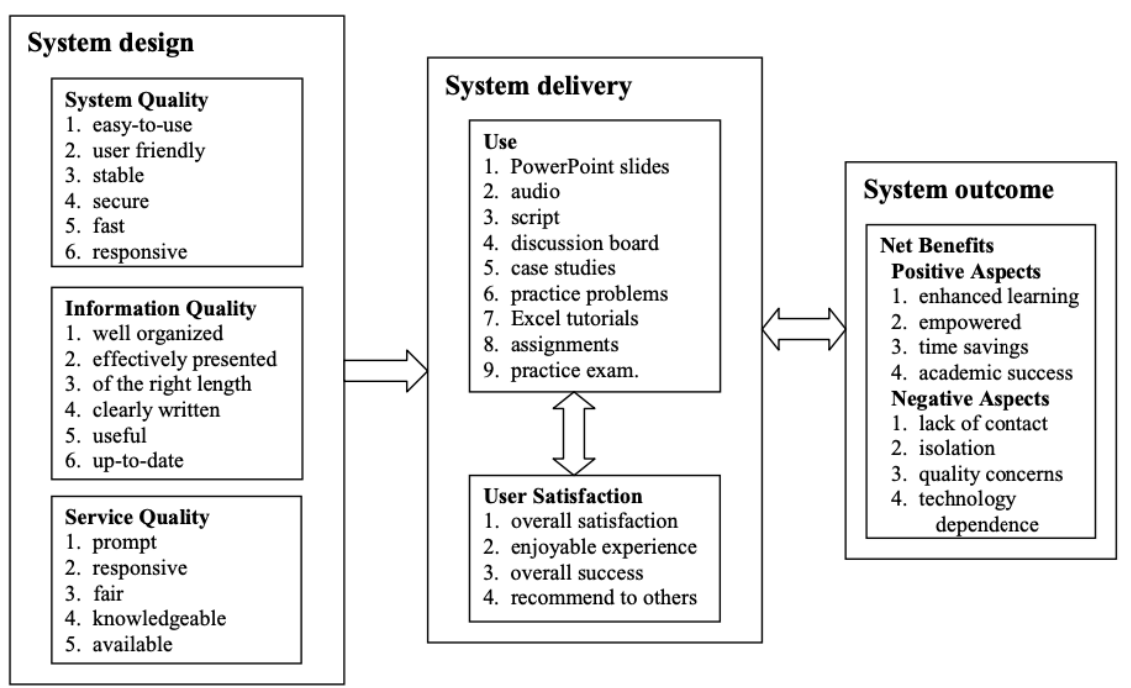

This research presents a qualitative study of the elements of the DeLone and McLean (2003) model applied to five Australian university case studies. We examine the potential of learning analytics to deliver appropriate functionality and usability to create an information system that delivers actual value to students.

\section{Research Approach}

The case study research method is well-suited to the purposes of this project. The method produces a rich description of the use of learning analytics at five universities that can be compiled and used to gain insights into the strengths and weaknesses of the five implementations (Merriam, 2014). The end product of the study is a rich description of the phenomenon under study. This might help the reader expand their understanding of the 
phenomena under study (Merriam, 2014). The case study approach has been used to good effect across a wide range of disciplines over decades, in projects seeking to understand complex issues. This current research aligns with the perspectives associated with the case study approach. Yin (1984) defines case study research as "an empirical inquiry that investigates a contemporary phenomenon within its real-life context; when the boundaries between phenomenon and context are not clearly evident"; and in which multiple sources of evidence are used (Yin, 1984, p. 13).

Case studies are used in research because they offer insights not available with other approaches (Rowley, 2002). As the generalisability of the case study approach is sometimes questioned, it is advisable to establish validity by cross-referencing multiple case studies. Multiple cases are equivalent to multiple experiments as opposed to having a single case or single experiment (Rowley, 2002). Case studies work well with exploratory investigations where there is little or no prior knowledge of reality or of a phenomenon (Järvinen, 2001). Qualitative methods like this allows real-world events to be studied in context. This includes the cultural aspects of people, organizations, and groups. It is important that culture, that is, the implicit rules governing the social behaviour of groups of people is considered (Yin, 2011). The world will be viewed interpretively as a social construction of reality as experienced by people and their interactions within the wider social systems.

Qualitative analysis was performed using exploratory thematic analysis. Thematic analysis is a flexible and well used qualitative analytic method that search for themes or patterns in qualitative data (Braun \& Clarke, 2006). Interview questions used for the DeLone \& McClean model were formulated based on the work of similar qualitative studies and mapped to quantitative categories (Ojo, 2017; Hopsapple \& Lee, 2006; Wang, et al., 2007). The interview questions were analysed using both open and axial coding of the responses and this served as the primary means of analysing the qualitative data (Braun \& Clark, 2006). The interview protocol included 32 questions categorised into background data, systems quality, information quality, service quality, intention to use/use, user satisfaction and net benefits (impact). In addition to the categories in the updated (2003) DeLone $\&$ McLean model, questions about the impact of the system on teaching and learning were added.

\section{Case Studies}

Case Study data was collected from five demographically diverse Australian universities, three of which were metropolitan and two being regional or a mix of regional/metropolitan. The demographic spread of the data sources provides an inclusive view of the learning analytics implementations in Australian universities. Five participants from each university were interviewed. Interview participants were recruited based on recommendations of the first interview participant - who was usually the manager of the LA department. Participation was entirely voluntary. The roles of participants ranged from three main areas: (1) academics, (2) LA managers or department heads and (3) LA support staff.

University one is a regional university which services an extensive agricultural region. Given its remoteness from major population areas, it specialises in online programs. In this it has earned an excellent reputation. The great proportion of enrolments are online students. These come from varying backgrounds, including low socioeconomic status (SES), first-in-family, mature aged and professionals seeking career enhancement. University two is a metropolitan public research university with a low to middle SES catchment. A higher than average proportion of its students are first in family, some with special needs. In some cases, students have a lower entrance score than those of their immediate counterparts. University Three is a regional public university with campuses in multiple Australian states. Like University one, it specialises in online service delivery, for which it is a recognised leader in the Australian context. This university draws its students from diverse background across regional Australia, including low SES, first-in-family, mature aged and professionals. University Four is a metropolitan public research-intensive university servicing a middle to high SES demographic. This 'Group of Eight' university is perceived locally and internationally as prestigious. It routinely attracts students with high entrance scores. University Five is also a metropolitan public research-intensive university. It was established in the 1980's during the Dawkins reform when Institutes around Australia were transformed into Universities.

\section{Research Results}

In order to explore the information system success of learning analytics systems, interview participants were specifically asked questions framed according to the DeLone \& McLean Model. Initially, respondents were asked about the types of learning analytics systems implemented at their respective universities. At the end of the interview, participants were asked to describe (a) any perceived benefits that the learning analytics systems brought to their learning and teaching, (b) the learning and teaching overall at the university, (c) its impact on the effectiveness and productivity of the university and (d) overall net benefits to learning and teaching. 


\section{Types of Learning Analytics Systems}

We observed significant variation in the approaches to learning analytics across the five case study sites. University One has two clear systems, one of which is centred around a student evaluation system and the other is a teaching analytics system that was embedded in the Learning Management System (LMS). University Two has a dedicated learning analytics system integrated in with the LMS. This service is available to staff for the purpose of learning and teaching process improvement. In addition to and separate from this first system is an analytic system used by a strategic business unit. No integration between the two system was observed. University Three originally had a proprietary system that had been discontinued because the data outputs had proven misleadingly inaccurate. They now operated an internally developed learning analytics system, the design of which had been informed by lessons learned from what had worked and not worked in the first system. In University Four the learning analytics system centres on a risk and quality model. Said system uses a proprietary analytics tool to generate analytics on demand to staff and students, both of whom have access to customisable dashboards. University Five does not currently have a central learning analytics system although they do have plans to implement one in the near future, most likely in the 2020/21 financial year (COVID recovery permitting). In the meantime, staff derive data from various systems including the LMS to inform their teaching.

\section{Information Quality}

Many interview participants observed that reports from the learning analytics systems could not be customised. The implication was that the usability of the system would be improved if customisation were possible. In a very few cases, a small amount of customization was possible. One participant at University Two noted that customization might cause useful information to be overlooked because the user might not be aware of the full range of capabilities. University Three had '... really good feedback from our team'. Customization was not a major factor in the design of learning analytic systems currently. At University Three, the earlier information quality issues had been solved by replacing the proprietary system with an in-house developed system.

\section{System Quality}

Across the five universities, the performance of the learning analytics system was perceived to be adequate. In a couple of cases, participants reported that the system could lag if the numbers enrolled in the course (class) was large. If the course/subject was small, then the performance was adequate. One participant noted 'The performance of the system was reported as automatic with no lagging. The accuracy of data was reported to be $100 \%$ accurate. They have a 24 -hour turnaround on any data queries. For these users the data is accurate and reliable. Also, we're working with one single point of truth.' This participant was very confident in the accuracy of the system.

A university two participant noted that the system was 'Not that easy. I sort of have to find my way through every time I want to go and use it. I think it could be a lot more intuitive. Yeah, I don't find it that easy to use.' It was reported that it was difficult to access although one teaching staff member said if you access the basic stuff, then it is easy to access but overall, the system was complex. 'I honestly get lost just about every time trying to find the analytics'. Overall, the information outputs from the system were reported to be accurate by most participants.

An interviewee from university three described how they built their own custom system out of necessity due to the LMS producing inaccurate data little better than the output from a random number generator. Careful checking occurred with the custom-built system, which is considered reliable by users, but reservations remain. 'So, we've done a lot of data validation. I have just learnt never to trust data'. Data accuracy was perceived to be an important factor in the perception of learning analytic systems.

A rather different approach was taken at University One where reports are produced as PDF on request for users by the data analytics team. The data is up to date but not live. This system enforced mandatory use where all academics were required to use it but staff were reported to be very accepting of the system. 


\section{Service Quality}

In University One, learning analytic data had been used as a performance management tool. Underperforming staff could be identified and in some cases punished. There had been a negative perception for this reason. In more recent times, a major cultural shift has been observed. Staff now accept the system as being useful and full attendance was reported on training days. Intensive training sessions were instituted so that staff knew how to interpret the data constructively. Comprehensive how-to documentation was produced for staff. A website containing training videos was also set up. New staff can access these resources on-demand. It was reported that there was no downtime for maintenance, as the system was run through a data warehouse. Queries and/or adjustments are done through an established compliance process.

Staff interviewed from University Two did not engage with any of the formal training offered. They simply taught themselves how to use it for their needs. Comprehensive training is provided by the unit that offers professional development for staff. Multiple staff members were involved in the initial pilot of the system implementation, so they attended several training sessions. University Four offered formal training sessions regularly where attendance was good.

Prior to the current hybrid of systems implemented at University Three, they originally had a proprietary system that had been discontinued because the data outputs had proven misleadingly inaccurate. They now operate an internally developed learning analytics system, the design of which had been informed by lessons learned in the first system. A staff member reflects on the first time opening the analytic system 'It was horrendous then and like I remember the first time I opened it'. The system was ditched and a new one was developed in-house. Making the system simple was the main design requirement. The proprietary system is still used as the LMS at the university. The interview participant describes the new system as having so much more detailed information that can be accessed compared to before. The learning analytics manager reflects on the prior system 'So I'd go to subjects that I knew and look at the [system] site, look at students and it was all a little bit funny. And we discovered that it wasn't actually set up properly, so for a couple of years. Yeah, for a couple of years the learning analytics at the entire university were using random number generators'. Data accuracy is a key is using these type of systems.

Even though university number five does not have a central learning analytics system, staff have created their own bespoke systems on an as-needs basis. An academic participant found the LMS analytics that produce reports within the software are not very accurate. Some staff members have expressed interest in putting lecture material on YouTube to get more accurate analytics. Another issue this participant raised was the accuracy of student click data where it was noted that; Our students are pretty cluey right, so they can open blackboard and just go for a run, and it'll trick the system or me into thinking that I'm doing it'. Therefore, analytics alone cannot be solely depended upon when designing student learning activities.

\section{Intention to Use/Use}

In speaking about the academics, a participant from University One noted 'They've come on board in droves, and I think they love it because it gives them lots of rich insight that they haven't had before.' The system was reported have a very high acceptance rate by staff evidenced by $100 \%$ attendance at training sessions and general feedback given to the learning analytics departmental manager.

A participant from university two noted that the data retrieved from the learning analytics system can be rather abstract. The data may need to be analysed to see how it connects with what is being taught. Another member of university two reported only using the learning analytics at a basic level, for tracking resource usage/site activity, as in how many times a link was accessed.

Staff at University three commented that ownership of data is problematic in that some users who want to access it are unable to. The cause appears to be political, the result of a silo-mentality between administrative units. As one participant noted, the 'ownership of the data can be quite powerful'. Who is the custodian of the data? 'Depending on your context, what a single field in your dataset means is very different.' Staff felt it really depends on who owns that dataset and who is responsible for maintaining it and you could get different answers, depending on who you ask. It was stressed that you must build a relationship with the custodians of the data to get access to the data. 
University Four has a student dashboard for access. It was originally trialled with a cohort of medical students. It was realised that the nature of the cohort, which program they are doing, is instrumental to how the dashboard is used. If the cohort is made up of high performing students, they will likely use the student dashboard differently from the way a mixed performing cohort of students might use it. This university uses Tableau (C), a Business Intelligence and analytics software package. The risk level of every course is tracked via this software and then fed back to the department head in each school. You can select any course and look at the risk factors on a scale of 1-3 and see whether the course is at risk. As an example of a risk factor could be declining class numbers or enrolment. Student evaluation data is also integrated into this system.

University Five does not currently have a central learning analytic system although they are considering options and formulating plans. There are various academics who are using their own type of learning analytic systems. One staff member talking about her plans to use a self-built learning analytic process asked if it would be possible to 'scaffold their analysis of unit plans or teaching plans and let that information come through? To me (she continued), it is like a survey quiz that organised the data and helped them give feedback as to each point, suggesting whether (the student) was ready to move to the next level.' Another participant in an executive position stated that whatever type of the learning analytic system they decide to implement, it will be informed by the most current, cutting-edge research in the area.

\section{User Satisfaction}

The majority of interviewees commented on the perceived need for a central learning analytic system. One that can extract data from multiple systems and aggregate it into some usable form. There appears to be significant issues in achieving this. As one participant said 'I'm probably dealing with learning analytics for maybe ten years now, different universities. And I don't see we've progressed terribly far. Ten years ago, we had these great ideas for creating you know these data pools and being able to draw on them to make for pictures of people. And the reality is it's just too bloody hard at this point because the vendors structure the data in different ways. And to bring it in into one pool, it is just a mud pool. It's not a clear pool.' When staff interviewed refer to the learning analytics system, in more cases that not, it is not just a single system, it is a collection of systems.

Staff at University two are satisfied with the system as it can identify solvable issues. For example, a marketing course had many aviation students enrolled in it. It was designed for marketing students and did not take into account the aviation context. One staff member expresses her love of the system and how it forces continual quality improvement 'And that's exactly why they love it, because they don't get cosy'. 'They', being staff members. Another staff member from the same institution noted 'It makes the lecturer, makes the teacher more informed. Which is always a good thing from our perspective.' Learning analytic systems challenge the traditional model of teaching.

\section{Net Benefits - Teaching and Learning focus}

In terms of whether the learning analytics system increases productivity and effectiveness, staff reported that the system was popular with management. A participant from University one observed 'You think you have to drag people kicking and screaming to these, but you don't the way that executives just turn up at these sessions.' The learning analytics systems contribute to better management and systemic change. Decision making has also improved. Another participant from University one noted that deep decision making could be made, not shallow decision making. Staff also thought that it was a bit soon in the implementation process to see whether the system improved teaching and learning.

In answer to the question, does the system contribute to the overall effectiveness and efficiency of the university, a teaching staff member notes 'Yeah, I guess so, because it does help you to sort of identify the students that are having problems and they're not content as opposed to, you know, just wondering why they're not showing up to class. You can see that they're not even engaging online. So I guess it does in that sense help because you don't have to remind students, respond to emails and things like that and see that they're not doing the work. Yeah, I guess it also helps in terms of assignments as well and marking, you know, if there was a difference between who will fail. But you can say that they haven't attended any classes.' Learning analytic systems help contribute to the management of classes.

Reflecting on the net benefits of the system, a University Two participant notes 'Look I think there's an old saying in business that you can't manage what you can't measure or what you don't measure (a quote attributed to Peter Drucker) so if you want to be in control and do things well then you need to measure what you're doing and there is no substitute for that'. A university three participant reflects 'At first I think it was like, oh good, 
learning analytics, that will solve the world. They will inform our learning design; they will inform our teaching. But now we're realising that they might assist. Hmm. I think knowing your cohort is far more important than some learning analytics when it comes to setting up subjects.' Software is meant to help humans rather than hinder (Gayeski, 1991).

A participant from University Five foresees 'developing up the dashboard and offering it to you as an academic was going to solve the problem without training you in how you might use that data and how it might inform your practice, but also making sure that the support services that were available were wrapped into it so we could offer you a really lovely tool from an IT perspective, a really shiny dashboard that you may or may not look at. And even if you did look at it and even if you understood what it meant, you might not necessarily have the mechanisms to do anything about the students who are at risk that you were observing or a policy framework that says, yes, actually, I am enabled to go and do these things.' More work is needed on the useability of learning analytics systems. Academics/teachers need to have access to easy to use software systems that give them the data they need. They don't need to be questioning how to use it or whether the data is inaccurate.

\section{Concluding Remarks}

This paper provides an in-depth account of implementations of learning analytic systems at five diverse Australian universities. The DeLone \& McLean (2003) model has been applied to each case study and the findings discussed. It explicitly explores each section of the DeLone \& McLean (2003) model including information quality, system quality, service quality, intention to use/use, user satisfaction and overall net benefits. The overall impact of system on teaching and learning has been added to the model's categorization as it is a major focus of "net benefits" for the purpose of this system is to improve teaching and learning.

In terms of this study's findings, considerable variation exists between stakeholder accounts. There is no general consensus across sites. A "silo mentality" appears to exist in which various universities do not talk to each other about their nascent use of Learning Analytics, preferring to "do their own thing" as it were. This is understandable given there is no generally accepted way that LA should be used. If an orthodox method existed, even a provisional one, then stakeholders would probably be using it. The absence of consensus points to the pressing need to tentatively establish such a method. DeLone's model might therefore offer some possibilities in this regard. It is too early in this project to posit such a method. This might form the basis of further research.

While learning analytics as a discipline and a technology has been around for at least a decade, it has not matured as might have been expected. Spurred on by current pressures in the time of COVID, the maturation of learning analytics has accelerated. It is becoming a useful tool in the efforts by universities to improve the quality of their teaching while constraining teaching resources at their current levels, or less.

\section{Reference List}

Alhadad, S. J. (2018). Visualizing Data to Support Judgement, Inference, and Decision Making in Learning Analytics: Insights from Cognitive Psychology and Visualization Science, Journal of Learning Analytics, 5(2), 60-85. https://doi.org/10.18608/jla.2018.52.5

Beynon-Davis, P. (2013). Business Information Systems, Palgrave. https://doi.org/10.1007/978-1-137-30777-4

Braun, V., \& Clarke, V. (2006). Using thematic analysis in psychology. Qualitative Research in Psychology, 3(2), 77-101. https://doi.org/10.1191/1478088706qp063oa

Campbell, J., \& Oblinger, D. (2007). Academic analytics: White paper. Educause. Retrieved from http://net.educause.edu/ir/library/pdf/pub6101.pdf

Colvin, C., Rogers, T., Wade, A., Dawson, S., Gasevic, D., Buckingham Shum, S., Nelson, K., Alexander, S., Lockyer, L., Kennedy, G., Corrin, L., \& Fisher, J. (2016). Student retention and learning analytics: A snapshot of Australian practices and a framework for advancement. Canberra, ACT: Australian Government Office for Learning and Teaching. Retrieved from https://research.monash.edu/en/publications/studentretention-and-learning-analytics-a-snapshot-of-australian

Coombs C.R., Doherty N.F. and Loan-Clarke, J. (2001). The importance of user ownership and positive user attitudes in the successful adoption of community information systems. Journal of End User Computing 13(4), 5-16. https://doi.org/10.4018/joeuc.2001100101

Dawson, S., Joksimovic, S., Poquet, O., \& Siemens, G. (2019). Increasing the impact of learning analytics, Proceedings of the 9th International Conference on Learning Analytics \& Knowledge, pp. 446-455. https://doi.org/10.1145/3303772.3303784 
DeLone, W. H.; McLean, E. R. (1992). Information systems success: the quest for the dependent variable. Information Systems Research. 3(1): 60-95. https://doi.org/10.1287/isre.3.1.60

DeLone, W.H., and McLean, E.R. (2003). The DeLone and McLean model of information system success: a ten-year update, Journal of Management Information Systems 19(4), pp. 9-30. https://doi.org/10.1080/07421222.2003.11045748

Donoghue, G. M, Horvath, J. C. \& Lodge, J. M. (2019). Learning analytics and teaching a conceptual framework for translation and application, Routledge, Oxon. https://doi.org/10.4324/9781351113038-2

Drachsler, H., \& Kalz, M. (2016). The MOOC and learning analytics innovative cycle (MOLAC): A reflective summary of ongoing research and its challenges. Journal of Computer Assisted Learning, 32, 281-290. https://doi.org/10.1111/jcal.12135

Drucker, P. F. (1995). Managing the non-profit organization: Practices and principles. Taylor \& Francis.

Gayeski, D. M. (1991). Software Tools for Empowering Instructional Developers, Performance Improvement Quarterly, 4(4), pp. 21-36. https://doi.org/10.1111/j.1937-8327.1991.tb00521.x

Greller, W., Drachsler, H. (2012). Translating learning into numbers: A generic framework for learning analytics. Journal of Educational Technology and Society, 15, 42-57.

Holsapple, C. W., Lee-Post, A. (2006). Defining, assessing, and promoting E-Learning Success: an information systems perspective. Decis Science Journal Innovative Education 4(1):67-85. https://doi.org/10.1111/j.1540$\underline{4609.2006 .00102 . x}$

James, R., Krause, K. L., \& Jennings, C. (2010). The first-year experience in Australian universities: Findings from 1994 to 2009 (Vol. 326). Melbourne: Centre for the Study of Higher Education, University of Melbourne.

Järvinen, P. (2001). On research methods, Juvenes-Print, Tampere, Finland.

Junco, R. \& Clem, C. (2015). Predicting course outcomes with digital textbook usage data, The Internet and Higher Education, 27(15), pp. 54-63. https://doi.org/10.1016/j.iheduc.2015.06.001

Krause, K. L., \& Coates, H. (2008). Students' engagement in first-year university. Assessment \& Evaluation in Higher Education, 33(5), 493-505. https://doi.org/10.1080/02602930701698892

LAK (2011). 1st International Conference on Learning Analytics and Knowledge, Banff, Alberta, as cited in George Siemens and Phil Long, "Penetrating the Fog: Analytics in Learning and Education" EDUCAUSE Review, 46(5); New Media Consortium and EDUCAUSE Learning Initiative, NMC Horizon Report: 2012 Higher Education Edition.

Leclercq, A. (2007). The perceptual evaluation of information systems using the construct of user satisfaction: case study of a large French group. The DATABASE for Advances in Information Systems 38(2), 27-60. https://doi.org/10.1145/1240616.1240621

Mangaroska, K, Giannakos, M. (2019). Learning analytics for learning design: A systematic literature review of analytics-driven design to enhance learning. IEEE Transactions on Learning Technologies, 12, 516-534 https://doi.org/10.1109/TLT.2018.2868673

Merriam, S. B. (2014). Qualitative research: a guide to design and implementation, 3 Ed, Wiley, Hoboken.

Nguyen, T. D., Nguyen, T. M., \& Cao, T. H., (2015). Information Systems Success: A literature review, Springer International Publishing Switzerland 2015, T.K. Dang et al. (Eds) FDSE, LNCS, (9446) 242-256. https://doi.org/10.1007/978-3-319-26135-5 18

Ojo, A. (2017). Validation of the DeLone and McLean Information Systems Success Model, Health Inform Res. (1): 60-66, https://doi.org/10.4258/hir.2017.23.1.60

Petter, S., DeLone, W., \& McLean, E. (2008). Measuring information systems success: models, dimensions, measures and interrelationships, European Journal of Information Systems, 17(3), 236-263. https://doi.org/10.1057/ejis.2008.15

Rowley, J. (2002). Using case studies in research. https://doi.org/10.1108/01409170210782990

Rubel, A., \& Jones, K. (2016). Student privacy in learning analytics: An information ethics perspective. The Information Society, 32(2), 143-159. https://doi.org/10.1080/01972243.2016.1130502

Scheepers, S. R., Scheepers, H. and Ngwenyama, O. K. (2006). Contextual influences on user satisfaction with mobile computing: findings from two healthcare organizations. European Journal of Information Systems 15(3), 261-268. https://doi.org/10.1057/palgrave.ejis.3000615

Siemens, G., Dawson, S. \& Lynch, G. (2014). Improving the quality and productivity of the higher education sector: policy and strategy for systems-level deployment of learning analytics, https://www.voced.edu.au/content/ngv\%3A64739

Universities Australia (2020). Universities Australia Submission: Submission to Senate select committee on COVID-19. https://www.universitiesaustralia.edu.au/wp-content/uploads/2020/07/200528-UniversitiesAustralia-Submission-to-the-Senate-Committee-on-COVID-19-response.pdf

Wang, Y.-S., Wang, H.-Y., \& Shee, D. Y. (2007). Measuring e-learning systems success in an organizational context: Scale development and validation. Computers in Human Behavior, 23(4), 1792-1808 https://doi.org/10.1016/j.chb.2005.10.006 
West. D., Huijser, H., Heath, D., Lizzio, A., Toohey, D., Miles, C., Searle, B., Bronnimann, J. (2015). Learning Analytics: Assisting Universities with Student Retention - Literature Review.

https://researchrepository.murdoch.edu.au/id/eprint/35134/

Xing, W., Guo, R., Petakovic E., \& Goggins, S. (2015). Participation-based student final performance prediction model through interpretable Genetic Programming: Integrating learning analytics, educational data mining and theory, Computer in Human Behavior, 47, pp. 168-181, https://doi.org/10.1016/j.chb.2014.09.034

Yin, R. K. (1984). Case Study Research: Design and Methods, Beverly Hills, Sage Publications, California.

Yin, R. K. (2011). Qualitative Research from Start to Finish, The Guilford press, New York.

Clarke, J., \& Tuffley, D. (2021). Implementing learning analytics: The journey to improve teaching and learning at five Australian universities. In Gregory, S., Warburton, S., \& Schier, M. (Eds.), Back to the Future - ASCILITE '21. Proceedings ASCILITE 2021 in Armidale (pp. 1-10). https://doi.org/10.14742/ascilite2021.0101

Note: All published papers are refereed, having undergone a double-blind peer-review process.

The author(s) assign a Creative Commons by attribution licence enabling others to distribute, remix, tweak, and build upon their work, even commercially, as long as credit is given to the author(s) for the original creation.

(C) Clark, J \& Tuffley, D. 2021 